\title{
THE
}

\section{The impact of vertical public health initiatives on gendered familial care work: public health and ethical issues}

Zahra Meghani

University of Rhode Island, meghaniz@uri.edu

Follow this and additional works at: https://digitalcommons.uri.edu/phl_facpubs

The University of Rhode Island Faculty have made this article openly available.

Please let us know how Open Access to this research benefits you.

This is a pre-publication author manuscript of the final, published article.

Terms of Use

This article is made available under the terms and conditions applicable towards Open Access Policy Articles, as set forth in our Terms of Use.

\section{Citation/Publisher Attribution}

Meghani, Z. (2021). The impact of vertical public health initiatives on gendered familial care work: public health and ethical issues. Critical Public Health. https://doi.org/10.1080/09581596.2021.1908960

Available at: https://doi.org/10.1080/09581596.2021.1908960 


\section{Cite as}

Meghani, Z. (2021). The Impact of Vertical Public Health Initiatives on Gendered Familial Care Work: Public Health and Ethical Issues. Critical Public Health. https://www.tandfonline.com/doi/full/10.1080/09581596.2021.1908960

\section{The impact of vertical public health initiatives on gendered familial care work: Public health and ethical issues ${ }^{1}$}

\section{Introduction}

There is a growing body of research on the impact of vertical public health initiatives on low-income countries. This essay argues that projects that examine the impact of vertical public health ventures on the national health systems of low-income countries should also evaluate their effect on the familial caregiving responsibilities of women and girls from poorer households. By making that case, this paper aims to foster conversation between researchers who study vertical public health schemes and scholars who examine the impact of gendered care work norms, institutions, policies, and practices on women and girls from low-income households.

Health and disease status at the individual and population level are partially determined by socio-political-economic factors (WHO 2020). Inequitable power relationships between populations within nations and among countries tend to translate into socio-economically marginalized populations experiencing greater incidence of various diseases than groups that have socio-political and economic clout (WHO 2020). The higher incidence of diseases among the socio-economically marginalized usually means that the gendered familial caregiving responsibilities of females ${ }^{2}$ from those groups are amplified.

Horizontal public health approaches address interrelated health problems by strengthening health systems and integrating the delivery of specific medical interventions with other healthcare services and goods (Béhague and Storeng 2008). The adoption in the North of that approach to public health, along with social protection programs, has contributed to lower incidence and severity of multiple diseases. Consequently, among other things, women and girls from low-income households tend to have fewer gendered caregiving responsibilities for sick

\footnotetext{
${ }^{1}$ The author would like to thank the anonymous reviewers for their comments and Lindsay McLaren for editorial guidance.

${ }^{2}$ While the term "females" is used interchangeably with "women and girls", no essentializing claims are intended.
} 
family members than their counterpart from countries that have a fragmented, limited approach to healthcare provisioning and little or no social protection programs.

Unlike horizontal approaches to healthcare provisioning, vertical public health programs usually provide medical interventions for specific diseases by means of specialized service (Béhague and Storeng 2008). Vertical public health schemes are deployed in regions of the global South because certain Northern state and non-state actors frame them as rational and cost-

effective interventions for the poor of low-income countries. In reality such schemes undermine low-income countries' national health systems, including public primary care programs (see, for instance, Maeseneer et al. 2008; Storeng 2014; Mwisongo \& Nabyonga-Orem 2016). When the health systems of low-income countries are patchy or inadequate, poorer populations cannot get treatment for a range of medical conditions. Their illness tends to increase the gendered caregiving responsibilities of their female family members who must take care of them even as they attend to their usual care responsibilities (Gómez Gómez 2010). That has significance for those women's and girls' quality of life, including health. This gendered effect of vertical public health schemes merits research because it is an ethico-political and public health issue.

Next, the impact of gendered familial care work on women and girls from low-income households is discussed. It is also argued that vertical public health enterprises have negative implications for their health and other parts of their lives. The latter argument is likely to be contested by proponents of vertical public health schemes on the grounds that those ventures benefit the global South poor. In the interest of anticipating such objections, this commentary takes a two-step approach. First, it outlines the history of vertical public health initiatives, with the goal of making visible the interests that birth them. Second, it provides an overview of the research on the effects of those enterprises on the national health systems of poorer countries.

\section{Part One}

\section{Women and girls from low-income households and gendered familial care work}

Human survival and flourishing require direct care work of two kind: physical and affective (Kittay 2019; Tronto 2013). Physical direct care work includes domestic work, household management, and the physical labor of care for household members who have high dependency needs: the young, the sick, the elderly, or those who have disabilities. Human existence and thriving are also predicated on the availability of good quality affective care labor. 
In a 2014 report for the United Nations (UN) General Assembly, the Special Rapporteur on Extreme Poverty and Human Rights Magdalena Sepúlveda Carmona noted that women and girls from low-income households in the global South are obligated to undertake a disproportionate amount of unpaid direct (physical and affective) care work for their families, including the care of sick family members. Chopra \& Zambelli (2017) have discussed the toll on women from low-income households in India, Nepal, Rwanda, and Tanzania who have to manage their gendered familial care work responsibilities whilst also working outside the home for pay. As a rule, there is an inverse relationship between the amount and intensity of familial care work that women and girls perform and the time and capacity they have for self-care, leisure, and paid work (Sepúlveda Carmona 2014).

The burden of direct care work mostly rests on the shoulders of those women and girls because of gender norms, the inability of poorer families to purchase care services from the market, and the decision of states to not fund public programs to meet their impoverished populations' care needs. The latter choice of low-income countries may be attributable to factors such as international debt, limited resources, gender bias, etc.

The UN Special Rapporteur Sepúlveda Carmona has delineated the (ethico-political) obligation of states to respect the health rights of all persons, including those who do familial care work (2014, p.12):

The right to health requires States parties to provide quality and accessible health care and take measures to ensure the underlying determinants of health. This includes access to safe and potable water and adequate sanitation, an adequate supply of safe food, nutrition and housing, and also healthy occupational and environmental conditions, which clearly many unpaid caregivers living in poverty do not enjoy.

The gendered familial caregiving responsibilities of women and girls from poorer households in low-income countries usually increase when family members are sick but cannot get needed medical care from fragmented, under-resourced national health systems. The connection between the undermining of national health systems by vertical public health initiatives and the quality of life, including health, of those women and girls warrants research. 
Advocates of vertical public health enterprises might discount proposals for such research programs. They might contend that criticism of vertical public health ventures is not justified because they are the rational and financially sound approach to healthcare provisioning for the global South. To address such objections (and thereby argue for research programs that investigate the impact of vertical public health schemes on the gendered familial caregiving responsibilities of women and girls from low-income households), this commentary demythologizes vertical public health initiatives. To that end, it historicizes those enterprises, and then discusses the research on their impact on the national health systems of low-income countries.

\section{Part Two}

\section{A history of vertical public health interventions}

\section{The Alma-Ata Declaration}

In the 1950s and 1960s, following independence from colonial powers, many nations wanted to address the needs of their poor by providing comprehensive health care for everyone. They were motivated by a commitment to eliminate the inequities in health service availability and accessibility created by inadequate, fragmented public health programs that characterized colonial rule (such as ventures to eliminate malaria, and population control programs for the global South) (Sen \& Koivusalo 1998). ${ }^{3}$ The Alma-Ata Declaration recognized health as a human right. Governments were obligated to provide comprehensive primary health care, which included education about common diseases and injuries, and prevention and control measures. They had to provide to those within their borders with adequate and nutritious food, safe water, sanitation facilities, maternal and child healthcare, including family planning services, and immunization (WHO 1978).

The Declaration was a political document. It advocated de-centralized comprehensive primary healthcare programs for the poor that were community directed and responsive (Werner et al. 1997). It rejected gross inequalities within and among nations as 'politically, socially, and economically unacceptable' because such disparities accounted for high incidence of diseases and deprivation among the poor of the global South (Birn et al. 2017). The socio-politicaleconomic stance of the Declaration was rooted in the New International Economic Order (NIEO)

\footnotetext{
${ }^{3}$ Also see Litsios (2002) on the formulation of the Declaration.
} 
that was articulated by global South nations (Birn et al. 2017). The NIEO asserted the autonomy of former colonies. ${ }^{4}$

The subversion of the Alma-Ata aspirations: Neo-colonial 'medicine' for the South

The NIEO-based 1978 Alma Ata approach to public health was immediately dismissed by powerful Northern actors as irrational and financially unfeasible for the global South. The Rockefeller Foundation (RF) and the World Bank (WB) were some of its key critics. In 1979, supported by the WB, the RF sponsored the Health and Population in Developing Countries conference (Brown et al. 2006). The meeting was about healthcare provisioning of the poor of 'developing' countries, but it was held in Italy and dominated by North-based actors, such as the WB, the Ford Foundation, the U.S. Agency for International Development, and the Canadian International Development and Research Center.

At the meeting, two RF researchers presented a paper that framed selective primary healthcare as the rational, cost-effective alternative to comprehensive primary healthcare envisioned in the Alma Ata Declaration. The paper was one of the tools that North-based actors used to undermine the Declaration, and thereby, the NEIO principles. The paper's authors, Ken Warren (the RF Director of Health Services) and Julia Walsh (a visiting research fellow at the organization), claimed that the goals of the Declaration were noble, but unattainable and irrational because they were not cost-effective. They referenced a World Bank report that deemed the cost of providing basic medical care to the poor of the global South as unaffordable because it would be in the billions (Walsh \& Warren 1979, p.967).

The Foundation researchers contended that the global South did not have sufficient health care personnel. They also claimed that the measures required for the control of multiple infectious diseases would not work because it went against the 'culture' of the global South:

Proper sanitation and clean water make a substantial difference in the amount of disease in an area but the financial investment involved is enormous. The success of such (sanitation and clean water) projects also depends on rigorous maintenance and alteration

\footnotetext{
${ }^{4}$ That assertion elicited a strong response from some Northern actors. For instance, David Rockefeller (1975) was highly critical of the NIEO's stance that (global South) countries should be able to regulate and supervise the actions of transnational corporations within their borders.
} 
of engrained cultural habits (of the peoples of the South) (Walsh and Warren 1979, p.971).

As a 'reasonable' solution to multiple infectious diseases of poverty that would sidestep the problem of the 'culture' of former colonies, the RF researchers, the WB, and other Northbased global health governance actors proposed that global South nations should provide publicly funded selective primary care ${ }^{5}$ and rely on vertical public health programs. One of the criteria for determining which diseases should be targeted for intervention was the amount that the Foundation considered reasonable for global South nations to spend on public health problems that disproportionately affected poorer populations (Walsh \& Warren 1979). The espousal of vertical public health initiatives by Northern state and non-state actors could be understood as based on an unwillingness to address the social determinants of health and disease that were rooted in inequitable political and economic power relations between the former colonies and the dominant global actors.

In nations that were debtors of the $\mathrm{WB}$, the implementation of the Alma Ata public health approach was undermined or blocked in many regards by the neoliberal structural adjustment programs (SAPs) that they were required to adopt by the Bank and the International Monetary Fund (see, for instance, Pfeiffer and Chapman 2010). The structural adjustments prevented debtor nations from creating and maintaining social protection programs that could have reduced the gendered familial care work responsibilities of women and girls from low-income households. (Of course, such programs would leave unaddressed the gender inequities and dynamics that place the bulk of familial care work responsibilities on women and girls.)

To meet the SAPs requirements for the health care sector, low-income nations could only fund a very limited number of healthcare services and goods. States also had to hand-over the responsibility of provisioning of certain health care services and goods to non-governmental organizations (NGOs) and other private entities (Pfeiffer and Chapman 2010). Arguably, the decision to institute that reform was not actually made by governments of the South. Rather it was made for them as the WB, USAID and other major Northern donors began channeling significant portions of monies intended for health programs in the global South to North-based

${ }^{5}$ UNICEF had originally been a proponent of comprehensive primary healthcare. But, in the 1980s, it succumbed to the 'logic' of the SAPs. UNICEF's GOBI and later GOBI-FFF are selective primary healthcare programs. For a detailed analysis of the failings of those initiatives, see Werner et $a l .1997$. 
NGOs, rather than providing them directly to the governments of those countries (Pfeiffer and Chapman 2010). Over time that channeling of funding resulted in an explosive growth in NGOs in Africa (Pfeiffer and Chapman 2010).

\section{Part Three}

The impact of vertical public health initiatives on national health systems: Public health costs and ethical failings

Today, various global South nations have fragmented, inadequate national health care systems, comprising primarily of selective primary care programs and (certain) vertical publicprivate health initiatives. Such an approach disproportionately and negatively affects the life prospects of the poor including their health. The continuing push for that approach by Northbased global health governance actors is not justified given that the effectiveness of comprehensive primary health care programs as part of well-developed national health systems is known.

Vertical public health programs have been credited with saving millions of lives in lowincome countries, but there is another side to them. In a project that evaluated the impact of vertical public health enterprises that were part of Global Health Initiatives over a span of 20 years in Africa, Mwisongo \& Nabyonga-Orem conclude that little has changed in the approach of those ventures (2016, p.245). The programs mostly operate in a vertical manner, bypassing the health systems of the target nations, and influencing country policies to align with their narrow public health agenda.

Traditionally, North-managed NGOs have tended to keep the states and local communities that they target for their assistance at an arm's length in planning and designing interventions for them (although that has changed to some extent, and more for some initiatives than others). Such vertical public health programs concentrate authority in the hands of the managers of the program and their foreign state-based and private funders (Ooms et al. 2018).

The societally detached approach of such initiatives, presumably, is also reflected in the decision of those who fund or manage those programs to not integrate (or only work partially) with state-run public health programs. Some proponents of vertical public health enterprises appear to construe global South states that they parachute into as corrupt, inefficient, bound-up in red tape, and thus, ineffective and slow to respond to public health crises and needs (Storeng 
2014). As advocates of vertical public health initiatives present themselves to themselves and others as an alternative to the flawed or failed global South state and public health agencies, they act mostly or entirely autonomously from them. The target nation's state actors and even medical personnel usually have limited, if any, voice in significant fund use and intervention decisions (see, for instance, Cohn et al. 2011, pgs. 694-8 about the negative effects of Global Health Initiatives from the perspective of local civil society organizations).

In Mozambique, for instance, the multitude of vertical public health enterprises have created and worsened health inequalities (Mussa et al. 2013). The target disease effort receives a disproportionate amount of resources even as the national health care system is starved for basic resources. Piller and Smith (2007) write, "In Rwanda, only about 3\% of adults are infected (with AIDS) ... but more than 50\% of Rwanda's health budget, mostly from the Global Fund and other international sources was designated for AIDS."

Vertical public health programs poach health care workers from fragile, under-resourced public health programs (Mussa et al. 2013). For instance, the internal medical personnel braindrain in Ethiopia attributable to the Global Fund to Fight AIDS, Tuberculosis and Malaria (a vertical public health initiative) has had a devastating impact on the public health system, including primary health care services (Maeseneer et al. 2008, p.3). The siphoning-off of medical staff by vertical public health initiatives in various parts of Africa has resulted in "staff shortages (that) have abandoned many children of AIDS survivors to more common killers: birth sepsis, diarrhea and asphyxia" (Piller and Smith 2007).

As vertical public health schemes undermine efforts of global South nations to build national health systems, including well-developed primary health care programs, they undercut the efforts of those governments to respect the health right of their population (see earlier discussion of the 2014 report of the UN Special Rapporteur on Extreme Poverty and Human Rights Sepúlveda Carmona). So, this is a human rights issue.

Vertical public health enterprises reflect North-based funders' values and interests, and they are based on approaches that they espouse for public health problems of the global South poor. For instance, one of the Bill and Melinda Gates Foundation's latest vertical public health enterprise is Target Malaria. That venture aims to release patented genetically engineered mosquitoes in parts of sub-Saharan Africa as the solution to the high incidence of malaria among the poor even though that approach entails considerable uncertainty and risks (Meghani 2020). 
PEPFAR, for instance, places restrictions on condom promotion, sex worker education programs, and abortion (Pfieffer 2013). The establishment of the Global Fund weakened the important transnational movement for intellectual property reform that had grown in the late 1990s "to address the grossly immoral profiteering of pharmaceutical companies that impeded access to HIV/AIDS drugs in low- and middle-income countries, particularly in Africa" (Birn 2014, p.13). GAVI has been criticized for serving the interests of the pharmaceutical sector by over emphasizing new, novel, and expensive vaccines, rather than known to be effective basic vaccines (Birn 2014, p.13; Bruen 2018). Relatedly, a Regional Advocacy Officer at Doctors Without Borders noted that when GAVI "phases out funding for countries it supports, they (i.e., those countries) will still have to deal with the high prices charged by big pharma... they will (be) $\ldots$ at the ... negotiating tables with these (pharmaceutical) companies, and with lesser bargaining power than Gavi" (Ganesan 2019). ${ }^{6}$ Some vaccines present unjustified risks of very serious harm to young children, but they continue to be administered in poorer countries (Mogensen et al. 2017, cited in Loffredo \& Greenstein 2020).

Each vertical public health initiative creates its own bureaucracy, wasting monies and personnel (Mussa et al. 2013; Whyte et al. 2013). Some public health researchers have argued that the funds that are devoted to support vertical public health initiatives (and thereby the foreign NGOs administering those programs) should be used to support primary health care systems of low-income countries. Pfieffer (2013) contends that as the bulk of PEPFAR funding is not channeled directly through the public health system, but flows through transient and unsustainable international NGOs, it is an enormous lost opportunity to build comprehensive national health systems (also see Frenk (2010)).

However, it is questionable whether funds that are used for vertical public health schemes would be channeled by key health care governance actors towards building national health systems. The former kind of healthcare provisioning efforts are premised on an ideology that does not take seriously the idea that health (and thus, health care) is a human right. It stands in contrast to the egalitarian political philosophy, such as the one embodied in the Alma Ata Declaration and the NIEO, that provides the impetus for the creation of national health systems.

\footnotetext{
${ }^{6}$ See Bruen (2018) for a history and detailed analysis of Gavi's policies for when countries transition out of its program.
} 
Funders and managers of vertical public health enterprises acknowledge the need to fully integrate their work within the public health systems of low-income nations. But they remain focused on the diseases they have selected for intervention (Marchal et al. 2009). Analyzing GAVI's efforts to that end, Storeng (2014) has argued that its conception of public health system strengthening is at odds with the notion of such systems as core socio-political institutions and as mechanisms for alleviating social inequalities. It is even more circumscribed than the WHO's conception of public health systems as “'building blocks' to achieve more equitable and sustained improvements across health services and health outcomes" (Storeng 2014).

To sum up, the ethical and public health value of rigorous assessments of vertical public health schemes is undeniable. They hold them accountable for the harms they cause and may even impel them to be transparent to at least some degree about their decision-making. They can also be read as efforts to motivate those who fund and manage vertical public health programs to recognize that elected representatives of populations whose lives and health they effect should be at the head of the decision-making table. Given that vertical public health programs collect funds from state and non-state donors on behalf of the poor of the global South, their goal ought to be to serve them.

The scope of projects that evaluate the impact of vertical public health schemes on national health systems must be broadened to track their gendered impact. The reason is simple. Those ventures undermine health systems of low-income nations. Consequently, patients who cannot pay for their medical care and who have illnesses other than (or in addition to) the diseases targeted by vertical programs may only get inadequate or no medical care from the national health care system. A significant overlooked public health and ethico-political corollary of this state of affair is the negative impact of those persons' illness on their female family members who provide care to them while they are sick. The impact of the amplification of the gendered care work responsibilities on the health and lives of those women and girls should be studied.

\section{Conclusion}

This commentary has argued that analyses of the impact of vertical public health enterprises on national health systems should take into account their effect on women and girls 
from low-income households who provide care to sick family members who cannot afford needed medical care. This is a crucial public health and ethical issue. 


\section{References}

Béhague, DP, \& Storeng, KT. (2008). Collapsing the vertical-horizontal divide: An ethnographic study of evidence-based policymaking in maternal health. AJPH, 98(4), 644-649.

Birn, AE. (2014). Philanthrocapitalism, Past and Present: The Rockefeller Foundation, the Gates Foundation, and the Setting(s) of the International/Global Health Agenda. Hypothesis, 12(1), p. e8.

Birn, AE., Pillay, Y., \& Holtz, TH. (2017). Textbook of Global Health. Oxford UP.

Brown, TM, Cueto, M., \& Fee, E. (2006). The World Health Organization and the transition from "international" to "global" public health. AJPH, 96(1), 62-72.

Bruen, C. (2018). Politics \& Policy Processes of Global Health Partnerships: The Case of Gavi, the Vaccine Alliance (Diss). Available at: https://doi.org/10.25419/rcsi.10802996.v1

Cohn, J., Russell, A., Baker, B., et al. (2011). Using global health initiatives to strengthen health systems: a civil society perspective. Global public health, 6(7), 687-702.

De Maeseneer, J., Van Weel, C., Egilman, D., et al. (2008). Strengthening primary care: addressing the disparity between vertical and horizontal investment. BJGP 58 (546): 3-4

Chopra, D., \& Zambelli, E. (2017). No time to rest: Women's lived experiences of balancing paid work and unpaid care work. Institute of Development Studies. Available at: https://opendocs.ids.ac.uk/opendocs/handle/20.500.12413/13574

Frenk, J. (2010). The global health system: strengthening national health systems as the next step for global progress. PLoS Med, 7(1), e1000089.

Ganesan, A. (2019). The Inconvenient Truth About Pneumonia Vaccines. August 27. 
Available at: https://msf-access.medium.com/the-inconvenient-truth-about-pneumonia-vaccines$\underline{\mathrm{a} 1851 \mathrm{e} 224 \mathrm{~d} 9 \mathrm{~b}}$

Kittay, EF. (2019). Learning from my daughter: The value and care of disabled minds. Oxford UP

Litsios, S. (2002). The long and difficult road to Alma-Ata: a personal reflection. IJHS, 32(4), 709-732

Loffredo, J. \& Greenstein, M. (2020). Why the Bill Gates global health empire promises more empire and less public health. 30 Grain. Available at: https://www.grain.org/en/article/6511why-the-bill-gates-global-health-empire-promises-more-empire-and-less-public-health

Marchal, B., Cavalli, A., \& Kegels, G. (2009). Global health actors claim to support health system strengthening: is this reality or rhetoric?. PLoS medicine, 6(4), e1000059.

Meghani, Z. (2020). The Hard Sell of Genetically Engineered (GE) Mosquitoes with Gene Drives as the Solution to Malaria: Ethical, Political, Epistemic, and Epidemiological Issues in Global Health Governance. The Routledge Handbook of Feminist Philosophy of Science (pp. 435-457). Routledge.

Mogensen, SW, Andersen, A., Rodrigues, A. et al. (2017). The introduction of diphtheriatetanus-pertussis and oral polio vaccine among young infants in an urban African community: a natural experiment. EBioMedicine, 17, 192-198

Msuya, J. (2004). Horizontal and vertical delivery of health services: what are the tradeoffs. Background paper for the World Development Report.

Mussa, AH., Pfeiffer, J., Gloyd, SS., et al. (2013). Vertical funding, non-governmental organizations, and health system strengthening: perspectives of public sector health workers in Mozambique. Human Resources for Health, 11(1), 26. 
Mwisongo, A., \& Nabyonga-Orem, J. (2016). Global health initiatives in Africa - governance, priorities, harmonisation and alignment. BMC Health Serv Res 16, 212.

Ooms, G., Ottersen, T., Jahn, A., et al. (2018). Addressing the fragmentation of global health: the Lancet Commission on synergies between universal health coverage, health security, and health promotion.

Pfeiffer, J., \& Chapman, R. (2010). Anthropological perspectives on structural adjustment and public health. Annual Review of Anthropology, 39, 149-165.

Pfeiffer, J. (2013). The struggle for a public sector: PEPFAR in Mozambique. When people come first, 166-81.

Piller, C., \& Smith, D. (2007). Unintended victims of Gates Foundation generosity. Los Angeles Times, December 16. Available at:

https://www.latimes.com/nation/la-na-gates16dec16-story.html

Rockefeller, D. (1975). Multinationals Under Siege: A Threat to the World Economy. Stock Exchange, April 22.

https://digitalcollections.library.cmu.edu/awweb/awarchive?type=file \&item=403837

Sen, K., \& Koivusalo, M. (1998). Health care reforms and developing countries-a critical overview. The International journal of health planning and management, 13(3), 199-215.

Sepúlveda Carmona, M. (2013). Report of the Special Rapporteur on Extreme Poverty and Human Rights, United Nations, General Assembly, Sixty-eighth session, Item 69 (c) of the provisional agenda.

Storeng, KT. (2014). The GAVI Alliance and the 'Gates approach' to health system strengthening. Global public health, 9(8), 865-879. 
Tronto, JC. (2013). Caring democracy: Markets, equality, and justice. NYU Press.

Walsh J \& Warren K. (1979). Selective primary health care: an interim strategy for disease control in developing countries. NEJM 301:967-974

Werner, D., Sanders, D., Weston, et al. (1997). Questioning the solution: the politics of primary health care and child survival with an in-depth critique of oral rehydration therapy. HealthWrights.

Whyte, S. R., Whyte, M. A., Meinert, L., \& Twebaze, J. (2013). Therapeutic clientship: belonging in Uganda's projectified landscape of AIDS care. In When People Come First. Princeton UP, 140-166

World Health Organization. (1978). Declaration of Alma-Ata.

World Health Organization. (2020). Social determinants of health.

Available at: https://www.who.int/health-topics/social-determinants-of-health\#tab=tab_1 